\title{
Detection and Analysis of Particles with Failed SiC in AGR-1 Fuel Compacts
}

John D. Hunn ${ }^{\mathrm{a},{ }^{*}}$, Charles A. Baldwin ${ }^{\mathrm{a}}$, Tyler J. Gerczak ${ }^{\mathrm{a}}$, Fred C. Montgomery ${ }^{\mathrm{a}}$, Robert N. Morris ${ }^{\mathrm{a}}$, Chinthaka M. Silva ${ }^{a}$, Paul A. Demkowicz ${ }^{b}$, Jason M. Harp ${ }^{b}$, Scott A. Ploger ${ }^{b}$

${ }^{a}$ Oak Ridge National Laboratory (ORNL)

P.O. Box 2008, Oak Ridge TN, 37831-6093, USA

Phone:+001-865-574-2480,hunnjd@ornl.gov

${ }^{b}$ Idaho National Laboratory (INL)

P.O. Box 1625, Idaho Falls ID 83415-6188, USA

*Corresponding author 


\section{Introduction}

Development and qualification of tristructural isotropic (TRISO) coated particle fuel is part of the US Department of Energy's Advanced Reactor Technologies Initiative to promote scientific understanding and demonstrate the technical viability of high-temperature gas-cooled reactor technology. The AGR-1 experiment was the first in a series of US irradiation tests being performed on cylindrical compacts containing TRISO particles in a graphite matrix with kernels made up of a mixture of uranium carbide and uranium oxide (UCO) [Petti et al., 2010]. AGR-1 TRISO particles consisted of four concentric coatings on a 350-um-diameter spherical UCO fuel kernel: a low-density carbon buffer, a dense inner pyrolytic carbon (IPyC), a polycrystalline SiC, and a dense outer pyrolytic carbon (OPyC) [Lowden, 2006]. These layers were designed to contain actinides and fission products throughout the life of the fuel particle.

Post-irradiation examination (PIE) of AGR-1 irradiation test fuel has focused on evaluating the fuel performance during irradiation [Demkowicz et al., 2012] and during post-irradiation safety testing [Baldwin et al., 2014]. Fission product retention was one of the primary indicators of fuel performance that was studied. Rapid release of gaseous radioisotopes of krypton or xenon was used to monitor for TRISO coating failure in individual particles. Detection of this type of coating failure was an extremely rare event, with no occurrences during the three-year AGR-1 irradiation test of approximately 298,000 particles [Scates, 2010] and only two suspect particles in one of the fourteen safety-tested compacts (a compact tested at $1800^{\circ} \mathrm{C}$ ) [Demkowicz et al., 2015].

Release of a significant portion of an individual particle's inventory of cesium was used to detect the presence of particles with failed $\mathrm{SiC}$. Particles with through-layer pathways in the $\mathrm{SiC}$ that allow cesium to easily penetrate the layer will not rapidly release krypton or xenon if at least one pyrocarbon layer remains intact. Cesium release from four particles with failed SiC was observed in the PIE of the graphite holders that surrounded the compacts in the irradiation test capsules [Demkowicz et al., 2014]; three of these particles were recovered for further analysis discussed below. Three particles released cesium during $1600^{\circ} \mathrm{C}$ safety testing, and numerous particles released cesium during safety testing at 1700 and $1800^{\circ} \mathrm{C}$ [Morris et al., 2014]; many of these were also recovered for analysis.

\section{Identifying compacts containing particles with failed $\mathrm{SiC}$}

The AGR-1 irradiation test train consisted of six independently-monitored capsules, each containing twelve compacts in three stacks inside a graphite holder; analysis of these holders and other capsule components provided data on radioisotopic release from the compacts [Harp et al., 2012]. Collimated-gamma scanning of the graphite holders also provided information on the spatial distribution of this release. Two graphite holders showed regions of elevated ${ }^{134} \mathrm{Cs}$ in the vicinity of three compacts (e.g., Fig. 1). Additional analysis described below was performed on these compacts to determine the source of the elevated cesium release.

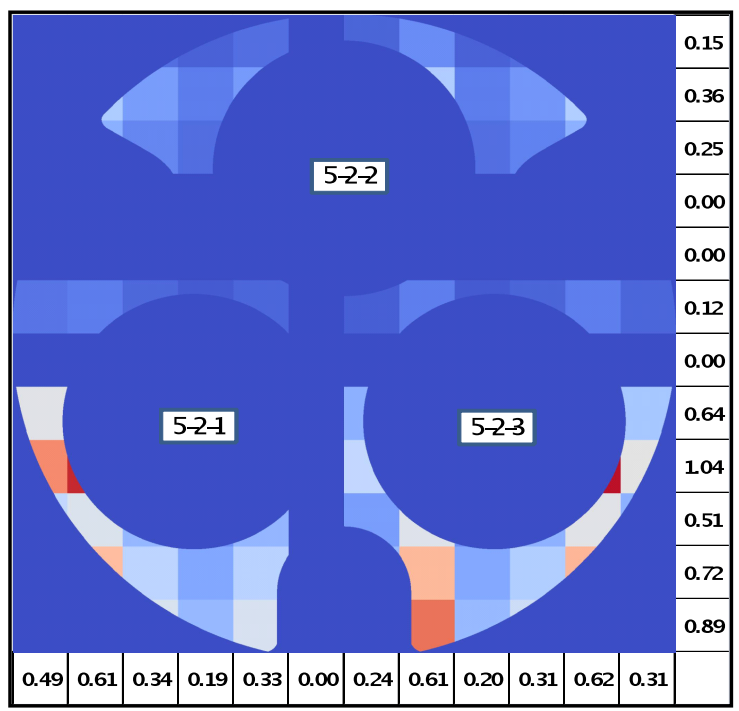

Fig. 1. Intensity map of ${ }^{134} \mathrm{Cs}$ activity in one section of Capsule 5 graphite holder showing hot spots (red) adjacent to Compacts 5-2-1 and 5-2-3 [Harp et al., 2012]. 


\section{Detecting $\mathrm{SiC}$ failures during post-irradiation safety testing}

After completion of the AGR-1 irradiation test, numerous compacts were subjected to post-irradiation safety testing in helium atmosphere to explore the fuel performance at maximum expected accident temperature during a depressurized conduction cooldown event $\left(1600^{\circ} \mathrm{C}\right)$ and at higher temperatures $\left(1700\right.$ and $\left.1800^{\circ} \mathrm{C}\right)$ to explore the fuel performance margin. During these safety tests, cesium release was monitored with water-cooled collectors that were periodically removed from the furnace and gamma scanned to measure condensed cesium. Fig. 2 shows the measured release rate for one of the $1600^{\circ} \mathrm{C}$ safety tests. In this test, a burst of cesium was detected soon after reaching $1600^{\circ} \mathrm{C}$ (presumably initiated by $\mathrm{SiC}$ failure in a single particle). After the initial release, the rate of cesium condensing on the cups slowly decreased back to background levels and the total integrated release was $68.5 \%$ of an average particle's inventory.

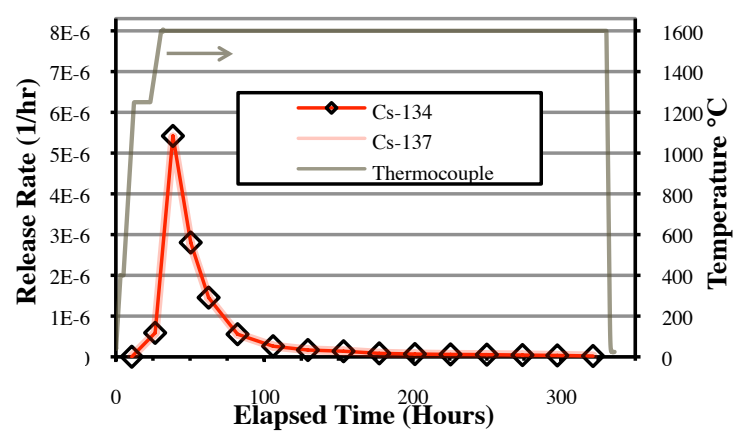

Fig. 2. Fraction of the compact's cesium inventory released per hour during $1600^{\circ} \mathrm{C}$ safety testing of AGR-1 Compact 4-1-2.

Cesium release was more complicated during $1800^{\circ} \mathrm{C}$ safety testing due to releases from multiple particles with failed $\mathrm{SiC}$, with failures occurring at varied times and each particle releasing a varied fraction of its cesium inventory (Fig. 3).

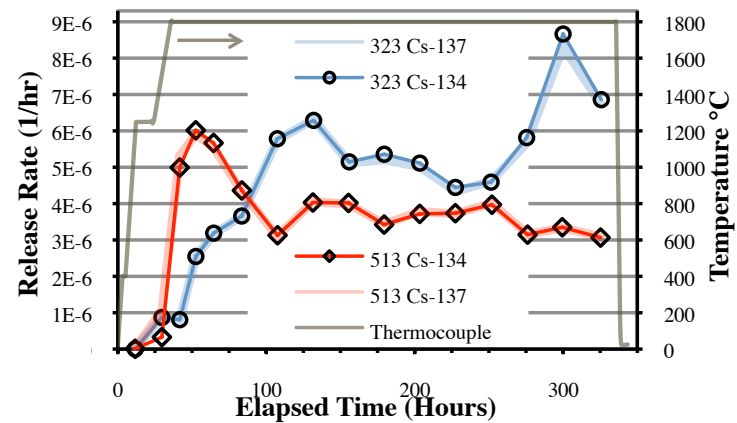

Fig. 3. Fraction of the compact's cesium inventory released per hour during $1800^{\circ} \mathrm{C}$ safety testing of AGR-1 Compacts 3-2-3 and 5-1-3.

\section{Isolating suspect particles with low cesium inventories}

As-irradiated and safety-tested compacts that exhibited cesium release indicative of failed SiC were subjected to electrolytic deconsolidation and acid leaching to separate the TRISO-coated particles from the encapsulating graphite matrix. In most cases, the particles were washed and dried for examination using the computerautomated ORNL Irradiated Microsphere Gamma Analyzer (IMGA). Detailed descriptions of the ORNL equipment and procedures relevant to IMGA and deconsolidation-leach-burn-leach (DLBL) are reported elsewhere [Baldwin et al., 2014]. The IMGA was used to survey the cesium inventory in every recovered particle. Particles were placed in glass jars and individually extracted with the IMGA vacuum needle for gamma analysis (Fig. 4). After a 50-100 s counting time, the relative inventories of ${ }^{137} \mathrm{Cs}$ and ${ }^{144} \mathrm{Ce}$ were used to sort particles, with programmed criteria to isolate particles that had inventories outside the normal distribution. The

${ }^{37} \mathrm{Cs}$ isotope was selected over the ${ }^{134} \mathrm{Cs}$ isotope for this survey because the longer-lived ${ }^{137} \mathrm{Cs}$ generated a stronger gamma signature at the time the PIE was performed (over a period corresponding to one to three ${ }^{134} \mathrm{Cs}$ half-lives after the end of irradiation). 


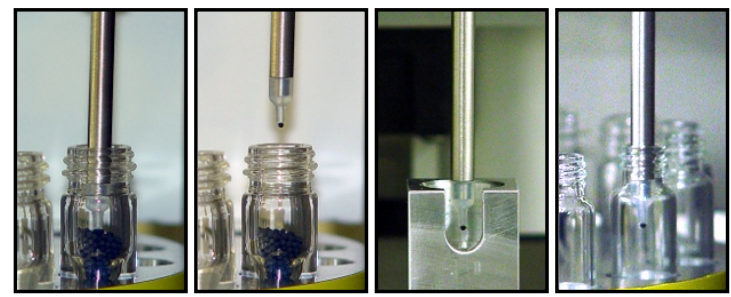

Fig. 4. Sequential images showing IMGA computer-automated vacuum needle selecting a single TRISO particle for gamma counting and depositing it into a designated vial after analysis.

As an example of the method, Fig. 5 shows the results from the IMGA survey of the Compact 3-2-3 particles recovered after $1800^{\circ} \mathrm{C}$ safety testing. Nine particles with cesium inventories from $13-80 \%$ of calculated were found to lie below the normal distribution and were automatically sorted out for further analysis. A few additional particles in the lower tail of the main distribution were also segregated for analysis.

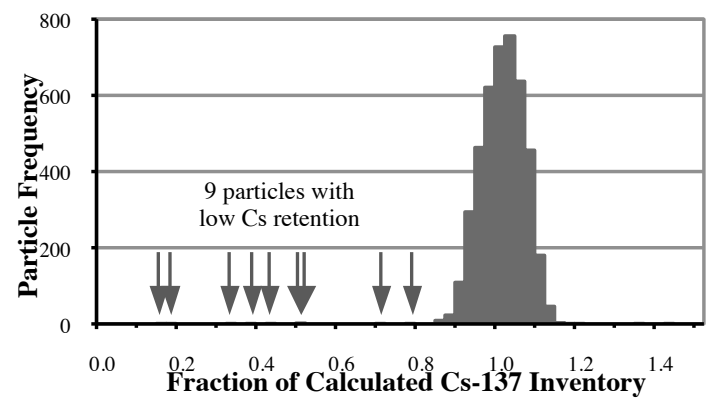

Fig. 5. Cesium inventory distribution determined with IMGA for particles from $1800^{\circ} \mathrm{C}$ safety-tested AGR-1 Compact 3-2-3.

\section{Analyzing failed $\mathrm{SiC}$ in Low-Cesium-retention Particles}

After using IMGA to isolate particles with significantly reduced cesium inventory, the particles were subjected to a series of analyses to investigate their internal microstructure. Particles were first imaged in three dimensions (3D) by non-destructive x-ray tomography, which was very effective at identifying the presence of through-layer anomalies in the $\mathrm{SiC}$, as well as providing detailed internal structure data for all the other layers and interfaces. Particles were then mechanically sectioned and polished for optical and scanning electron microscopy (SEM), using the 3D x-ray images to orient and guide the process; this approach offered a much higher probability that $\mathrm{SiC}$ failures could be successfully exposed for further study.

\subsection{Imaging SiC Failures with X-ray Tomography}

Detailed descriptions of the coated particle x-ray tomography equipment and method can be found in [Baldwin et al., 2014]. Fig. 6 shows a typical AGR-1 TRISO particle, where the only evident effects of the threeyear irradiation were a slight enlargement in kernel diameter and densification of the buffer layer, which caused it to detach from the IPyC. 


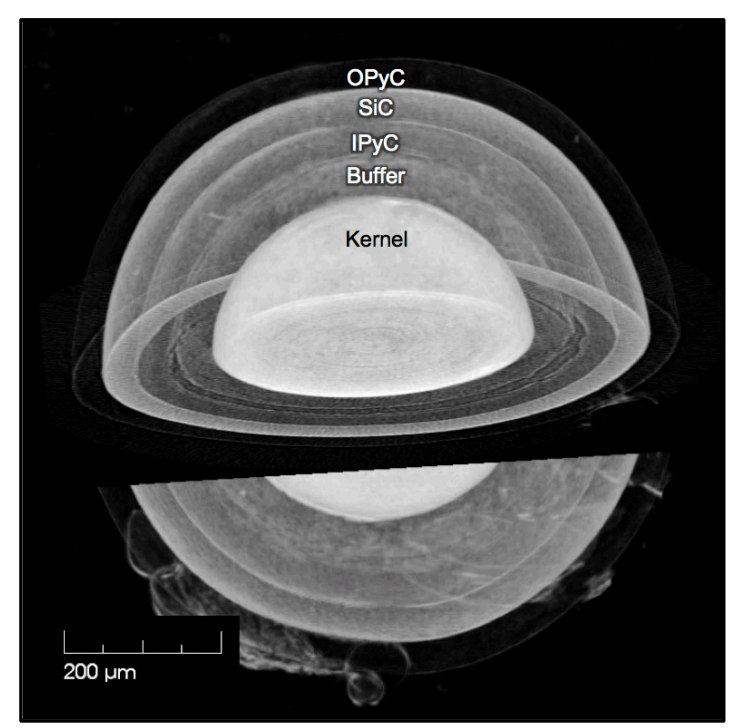

Fig. 6. Composite $\mathrm{x}$-ray image of a typical AGR-1 fuel particle from Compact 4-1-2; a 2D tomograph has been superimposed with a 3D visualization of the whole particle. Bright features at the bottom of the particle are from bubbles in the mounting epoxy.

More than twenty particles with failed $\mathrm{SiC}$ have been examined with $\mathrm{x}$-ray tomography, and only one failure mechanism has been observed in particles with coatings that conform to the intended AGR-1 TRISO design. Ironically, this failure mechanism was directly related to radiation-induced changes in the buffer, which traditionally is viewed as the least important layer for fission product retention. Densification of the buffer from fission product recoil and neutron irradiation is unavoidable at the high burnup and neutron irradiation doses experienced by the AGR-1 fuel particles [Demkowicz et al., 2014]. How the buffer responded to dimensional changes and interacted with the IPyC layer often determined whether the IPyC layer remained intact throughout the irradiation test.

Fig. 7 shows various ways that IPyC cracking in particles with failed $\mathrm{SiC}$ was either directly related to buffer fracture or to the shrinking buffer pulling away from the IPyC. Although buffer fracture or incomplete delamination from the IPyC only rarely resulted in IPyC cracking, evidence from materialography of AGR-1 particles suggests that strong bonding between the buffer and IPyC increased the likelihood for IPyC cracking and the spearhead-shaped fracture like that in Fig. 7a was observed in every particle that exhibited buffer fracture without buffer/IPyC debonding [Ploger et al., 2014]. Overall observation of the buffer/IPyC interaction in AGR-1 fuel particles has indicated that low interface strength to enhance buffer/IPyC debonding would be preferable and could further minimize cracking in IPyC layers like those in the AGR-1 fuel, where pyrocarbon anisotropy and density were successfully tailored to reduce radiation-induced cracking [Demkowicz et al., 2014].

Except for two particles with pre-existing, as-fabricated defects (discussed below), all observed SiC failures occurred where IPyC cracking exposed the inner surface of the $\mathrm{SiC}$. The x-ray images of the safety tested particles in Fig. 7 clearly show low-density regions (darker regions) penetrating the SiC where the IPyC cracks reach the $\mathrm{SiC}$ interface (the pathway through the $\mathrm{SiC}$ is less evident in the as-irradiated particle shown in Fig. 7c). Clusters of higher density material appear as bright spots in the images and are most prevalent in the areas around the degraded SiC. These clusters are identified in the SEM discussion below as predominantly Pd and U and presumed to be linked with localized corrosion of the SiC. Similar clusters are often observed in irradiated AGR-1 fuel at intact IPyC/SiC interfaces, but at lower concentration and without any obvious adverse impact on the $\mathrm{SiC}$ structure.

Fig. 7 shows protrusion of kernel material into some of the gaps between the buffer fragments. This was not unusual behavior in particles with fractured buffer and, in general, did not appear to be connected with failed SiC [Ploger et al., 2014]. However, Fig. 8 and Fig. 9 show a very unusual particle with failed SiC that was recovered after $1800^{\circ} \mathrm{C}$ safety testing where the kernel protruded through a spearhead fracture and reached the SiC layer, resulting in enhanced interaction. This is the only AGR-1 particle of this type that has been observed. 

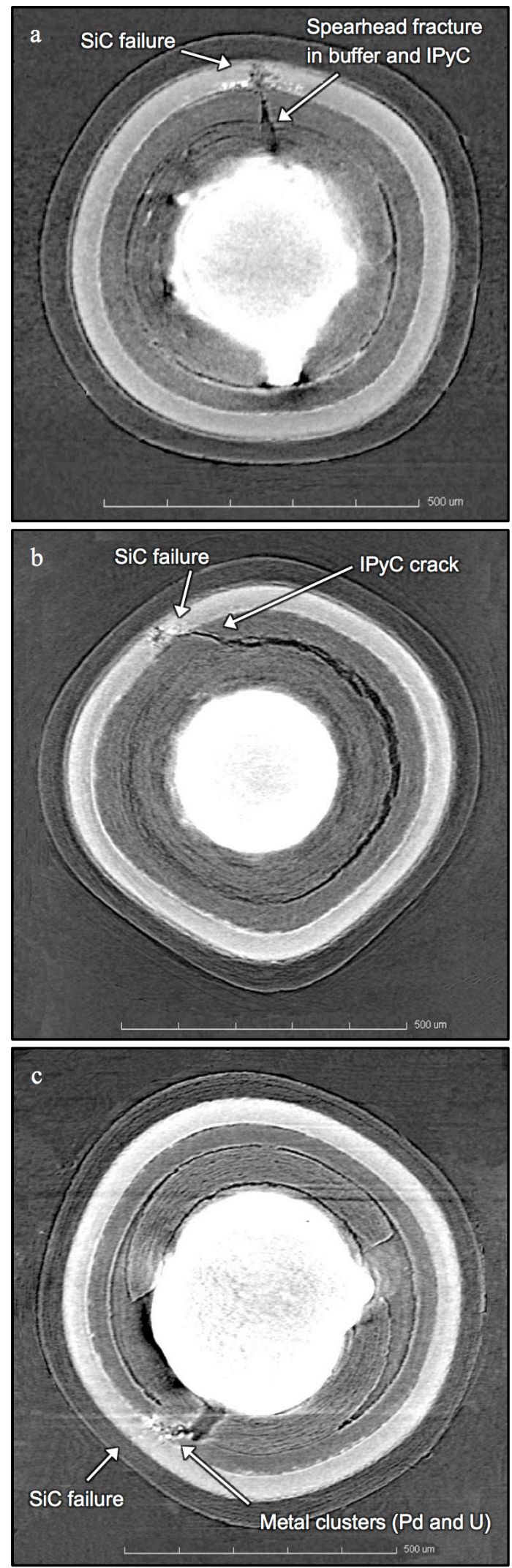

Fig. 7. X-ray tomographs of AGR-1 particles with failed SiC; (a) Compact 3-2-3 Particle 5 after $1800^{\circ} \mathrm{C}$ safety testing, (b) Compact 3-3-1 Particle 1 after $1700^{\circ} \mathrm{C}$ safety testing, and (c) Compact 5-2-3 Particle 2 after completion of AGR-1 irradiation test. 

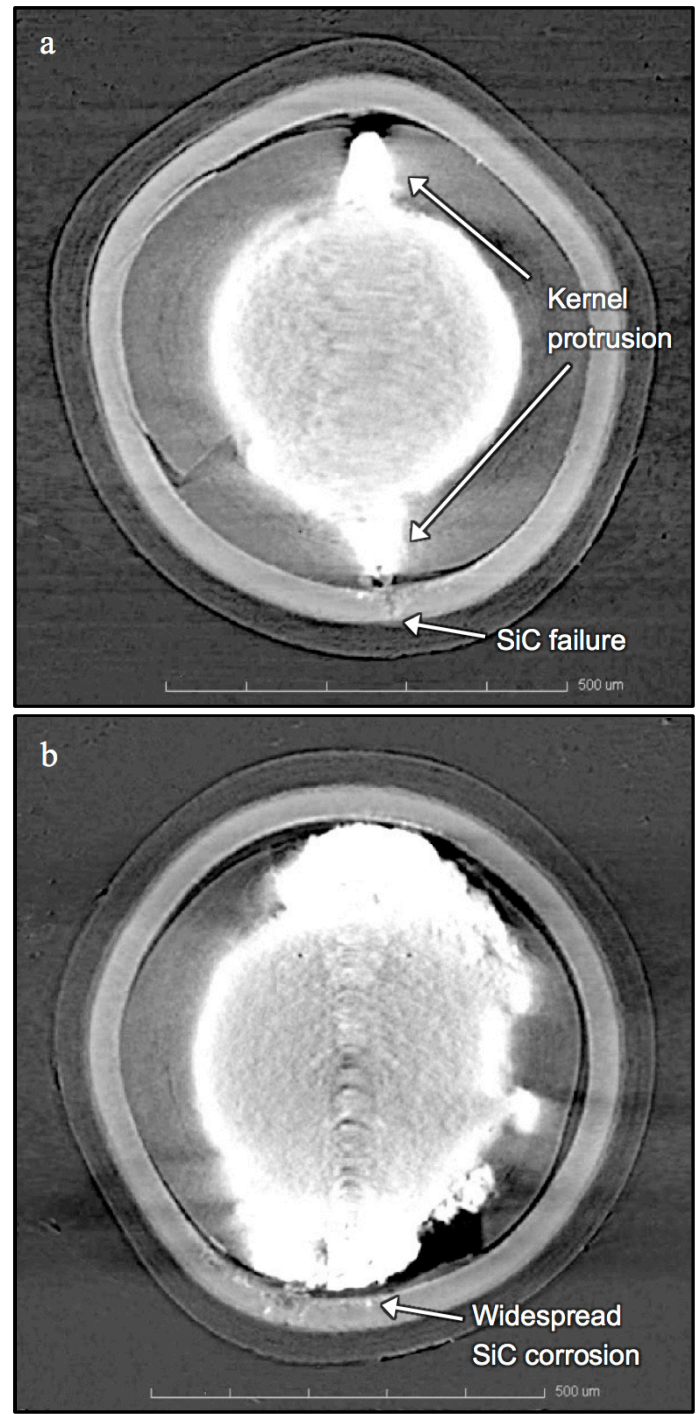

Fig. 8. Orthogonal $\mathrm{x}$-ray tomographs showing kernel protruding to the SiC in Compact 3-2-3 Particle 6 after $1800^{\circ} \mathrm{C}$ safety testing.

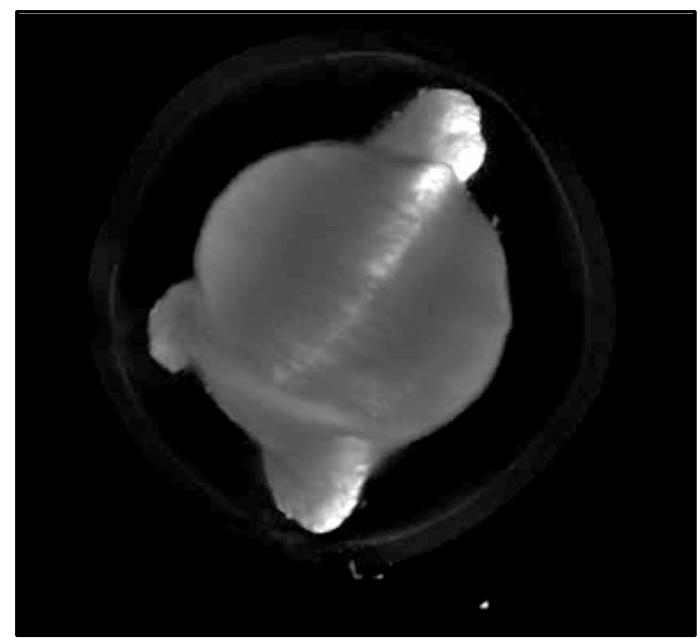

Fig. 9. Three-dimensional visualization of kernel surface in particle shown in Fig. 8 showing shape of kernel protrusion through buffer/IPyC fracture. 
Fig. 8a also shows delamination at the IPyC/SiC interface extending away from the IPyC crack and leading to tangential cracks in the $\mathrm{SiC}$. These $\mathrm{SiC}$ cracks ran circumferentially and did not result in a SiC failure. Similar structure has been observed in as-irradiated AGR-1 fuel particles without associated cesium release that would indicate that $\mathrm{SiC}$ cracks traversed the layer [Ploger et al., 2014]; in this particle, the $\mathrm{SiC}$ failure during $1800^{\circ} \mathrm{C}$ safety testing did not occur in the region with preexisting $\mathrm{SiC}$ cracks. Delamination at the IPyC/SiC interface has been observed most often when the buffer/IPyC interface remained intact and spearhead fracture occurred [Ploger et al., 2014].

As mentioned above, only two particles have been observed with $\mathrm{SiC}$ failure mechanisms different from the general mechanism of SiC exposure and chemical attack due to dimensional changes in the buffer cracking the IPyC. Both particles were recovered from compacts safety tested at $1600^{\circ} \mathrm{C}$ and exhibited $\mathrm{SiC}$ defects introduced during particle coating. Fig. 10 shows the particle that released cesium during safety testing of Compact 3-3-2; it had a malformed and very porous $\mathrm{SiC}$ layer that failed during safety testing. This fabrication defect was caused by momentary overfluidization of the particle between the IPyC and SiC coating steps, where the particle was ejected above the coating bed and picked up carbon soot from the chamber wall; subsequent SiC deposition infiltrated the soot and produced the abnormal structure. The presence of soot inclusions in the $\mathrm{SiC}$ was monitored as part of the AGR-1 quality control process and fluidization conditions were optimized to minimize the population and severity of these defects. Nevertheless, the fuel particle composite used in Compact 3-3-2 was known to have a small fraction $\left(\leq 10^{-3}\right)$ of these defects [Phillips et al., 2010], although most were much less severe and not expected to result in SiC failure like that observed in this unusually extreme example.

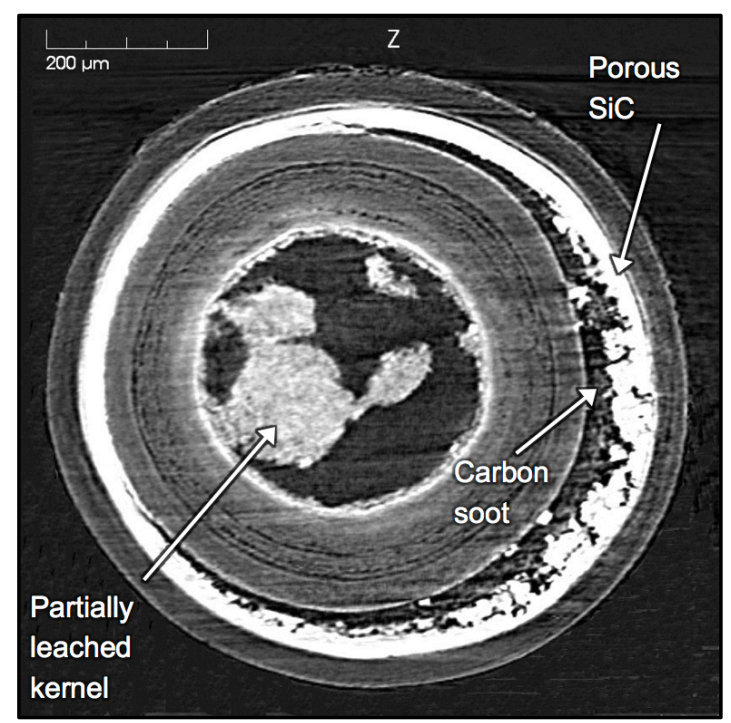

Fig. 10. Particle that released cesium during $1600^{\circ} \mathrm{C}$ safety testing of Compact 3-3-2.

Fig. 11 shows the particle that released cesium during safety testing of Compact 4-1-2; it also had a carbon soot inclusion, this time between the buffer and IPyC layers. The soot inclusion resulted in a noticeable dimple in the $\mathrm{SiC}$ layer. This type of fabrication defect was observed on rare occasion during characterization of AGR-1 fuel particles prior to irradiation, but the defect fraction was not specifically measured or limited by the fuel specification. During irradiation, the buffer and IPyC did not separate and appear to have fractured as a unit. Spearhead cracks through the buffer and IPyC led to regions of IPyC/SiC delamination, and fractures were observed in the $\mathrm{SiC}$ at the edges of these delamination regions that tended to curve around the particle in a circumferential direction but in some locations were connected to radial cracks through the layer (Fig. 11a). The $3 \mathrm{D}$ visualization of the $\mathrm{SiC}$ in Fig. $11 \mathrm{~b}$ shows that one continuous, through-layer crack circumscribes the particle and runs about halfway around the rim of the dimple; at the locations marked A and B, secondary cracks branch off and continue around the dimple but do not connect. 

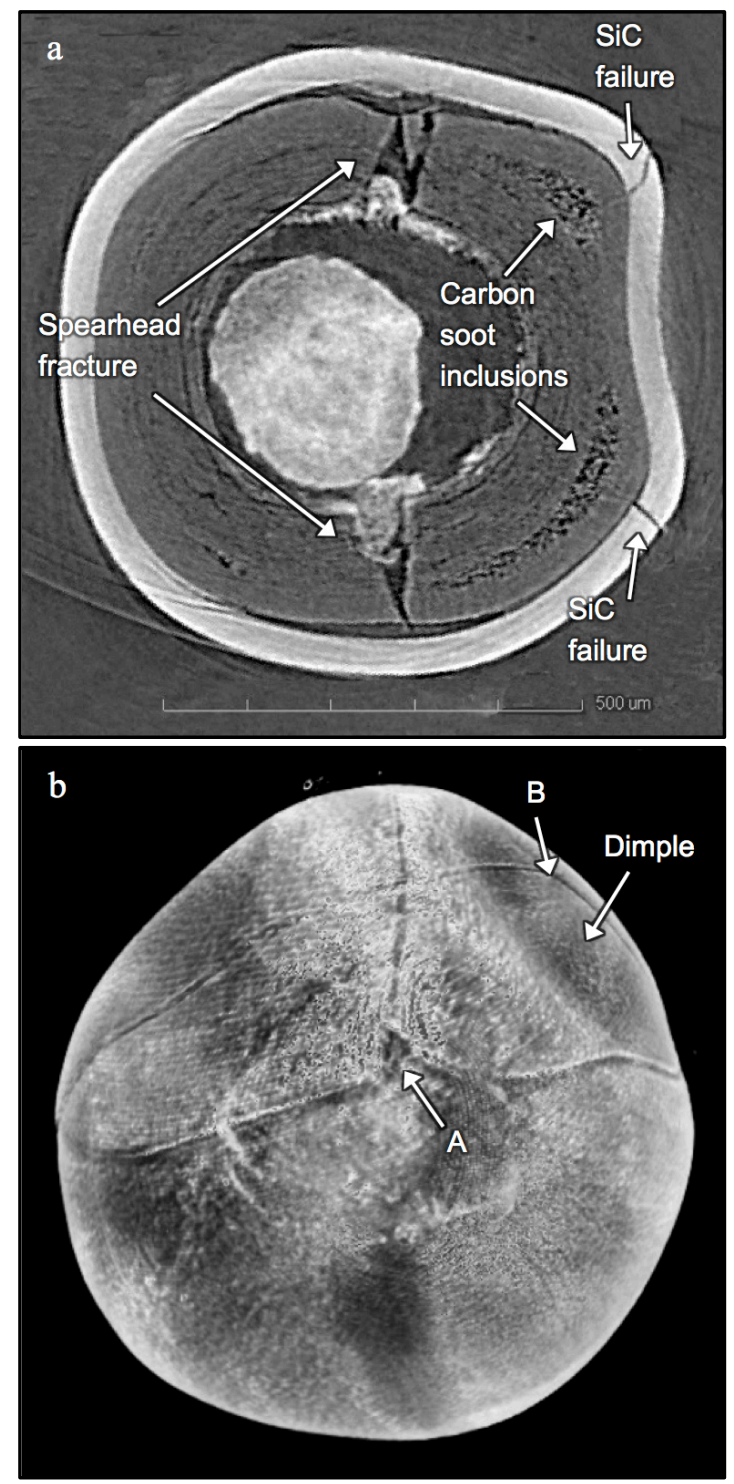

Fig. 11. Particle that released cesium during safety testing of Compact 4-1-2; (a) x-ray tomograph and (b) semitransparent $3 \mathrm{D}$ visualization of $\mathrm{SiC}$ surface.

Neither of the particles with $\mathrm{SiC}$ failures related to as-fabricated defects released cesium during the threeyear irradiation test (even with the extremely compromised $\mathrm{SiC}$ layer evident in Fig. 10), and both particles retained cesium until after reaching $1600^{\circ} \mathrm{C}$ during safety testing (e.g., Fig. 2). This indicates that, although most of the observed internal fracture, delamination, and dimensional changes presumably occurred during irradiation, $\mathrm{SiC}$ failure did not occur until additional stress was applied by the post-irradiation safety testing. The $\mathrm{x}$-ray images of these particles show partially missing kernels. Fig. 11a shows that the Compact 4-1-2 particle is missing its OPyC layer; exposed uranium detected during acid leaching indicated that the OPyC was initially intact during deconsolidation (consistent with no ${ }^{85} \mathrm{Kr}$ release during safety testing) but later broke off, allowing the acid to dissolve some of the kernel material. Similar acid leaching of the kernel appears to have occurred in the particle from Compact 3-3-2, but no cracks in the pyrocarbon layers were found.

\subsection{Sectioning of Particles with SiC Failures}

After $\mathrm{x}$-ray imaging, particles were mounted in epoxy and polished planar sections were prepared that revealed a portion of the $\mathrm{SiC}$ failure for detailed analysis. The 3D x-ray data was studied to determine the optimum mounting orientation, and successive tomographs perpendicular to the grinding direction were compared to optical micrographs of the exposed section to periodically monitor progress and successfully arrive at the target depth by matching up features such as fractures and debonds (Fig. 12). 

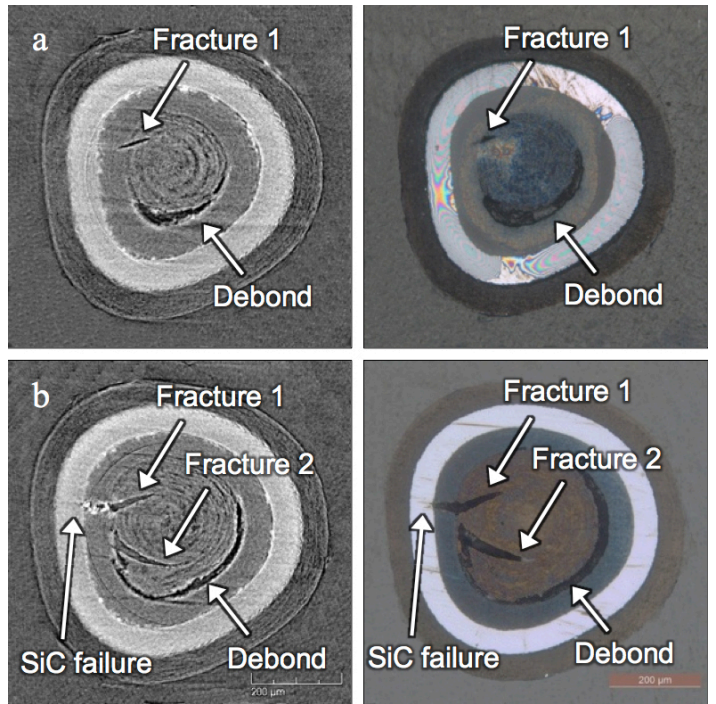

Fig. 12. X-ray tomograph/optical micrograph pairs showing how $\mathrm{x}$-ray imaging was used to guide materialographic preparation of the Compact 5-2-3 particle in Fig. 7c (grinding up from the bottom of that image). Optical images (right) show in-progress sectioning prior to final polish and cleaning.

Polished specimens were prepared in a dedicated materialography hot cell at ORNL that houses a Buehler Minimet ${ }^{\circledR} 1000$ grinder-polisher with the optional precision thinning attachment and a Leica DMI-5000 inverted optical microscope designed for remote operation (Fig. 13). Grinding and polishing was accomplished using metal-bonded-diamond discs and diamond lapping films. To minimize movement and drop out of loose fragments during grinding, void space was filled by vacuum impregnation with epoxy, typically during early grinding as soon as a buffer fracture or buffer/IPyC gap (if present) was sufficiently exposed to allow epoxy to flow down into the particle (e.g., Fig. 12a).

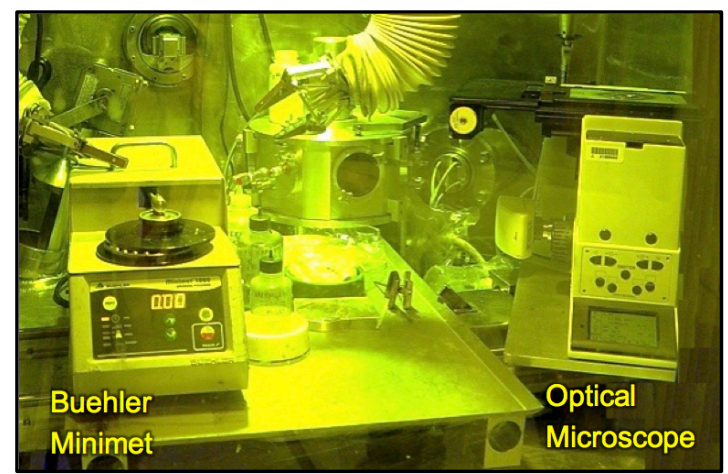

Fig. 13. Irradiated Fuel Examination Laboratory materialography hot cell.

Most materialographic sections were polished with 1.0-0.1-um-diamond lapping films prior to optical imaging. Fig. 14 shows a typical as-irradiated particle with various common features often observed in AGR-1 irradiated fuel particles. The polishing process was very successful in maintaining a flat surface and revealing the nature of the layer interfaces (intimate stitching between the IPyC/SiC and OPyC/epoxy was observed). Prior to SEM, optically-polished samples were further polished with a water-based, alkaline suspension of 0.04- $\mu$ mcolloidal silica to remove residual scratches and perform a mild chemical etch of the SiC. 


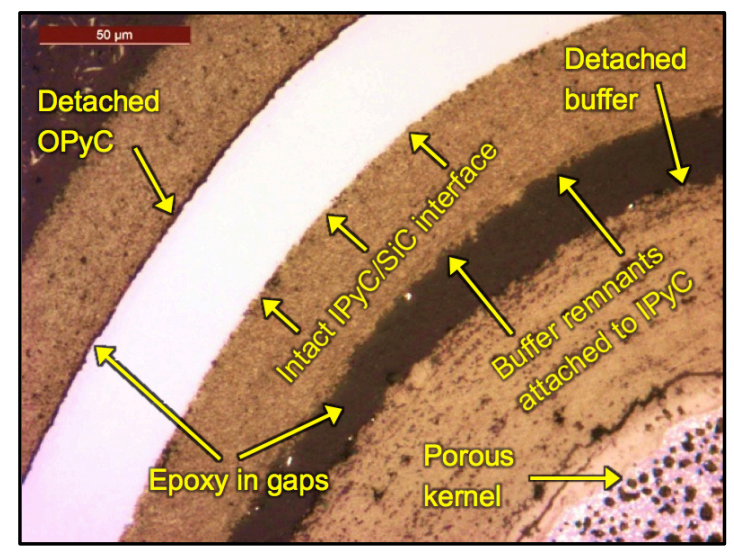

Fig. 14. Typical as-irradiated Compact 5-2-1 particle showing common features.

\subsection{Imaging SiC Failures by Optical Microscopy}

Optical microscopy provided additional detail of the region around the $\mathrm{SiC}$ failure, but was limited by the fact that the inherent three-dimensional structure could only be imaged in a single intersecting plane. Connecting pathways through the $\mathrm{SiC}$ layer were rarely visible in a single plane, so presumption of structure above and below the imaged plane must be inferred from the x-ray tomography data. Fig. 15 and Fig. 16 show planar sections that intersect the $\mathrm{SiC}$ corrosion found in two of the particles that released cesium during the AGR-1 irradiation test.

Particle 1 from Compact 5-2-3 (Fig. 15) shows a crack through the IPyC layer; on one side of this crack the buffer is still intimately bonded, while on the other side the buffer debonded by separating away from itself (leaving some residual material attached to the IPyC). IPyC cracks have often been found to be located at a buffer/IPyC delamination boundary like this and their formation can be presumed to be related to the debonding process. Foreign matter in the IPyC crack is discussed in the next section, where SEM analysis showed the presence of palladium which is presumed to have been the cause of the local degradation of the SiC layer. Damage in the SiC only penetrates about one-third of the way through the layer in this observation plane and $\mathrm{x}$-ray tomography could only marginally resolve a low-density pathway through the layer. However, cesium was released from this particle in concentrations too high to be explained by passage through intact $\mathrm{SiC}$ (based on the very low to non-existent cesium loss from particles and compacts in the absence of failed SiC). Presumably, there was damage deeper into the $\mathrm{SiC}$ layer in a plane above or below the image plane or a through-layer failure existed elsewhere in the particle. During grinding, a similar IPyC crack with clustered foreign matter and the onset of SiC attack was observed in Particle 2 from Compact 5-2-3 (Fig. 7c), but additional grinding did not unveil the suspected penetration.

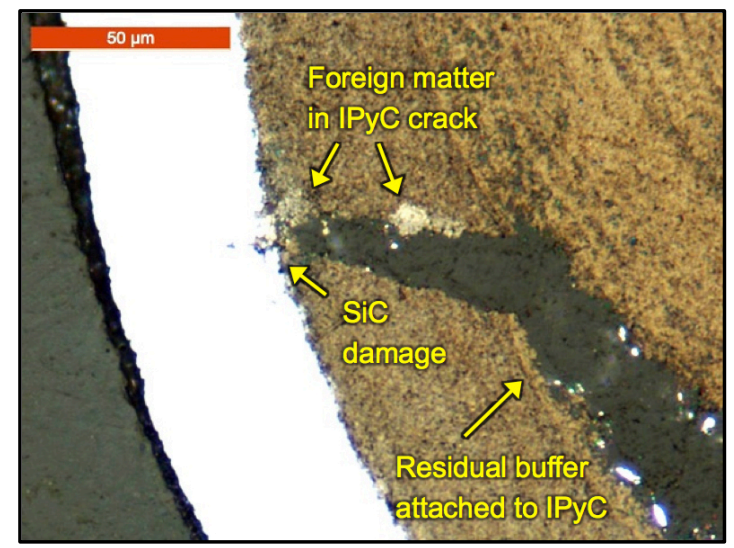

Fig. 15. Compact 5-2-3 Particle 1 with $\mathrm{SiC}$ that failed during irradiation testing.

The particle from Compact 5-2-1 that released cesium during the AGR-1 irradiation test showed a more obvious through-layer penetration in the x-ray imaging (Fig. 16a) and a large degraded area in the $\mathrm{SiC}$ was clearly evident while sectioning the particle. As grinding progressed through the damaged region, the position of the degraded area in the observed plane moved from the outer edge of the $\mathrm{SiC}$ toward the IPyC/SiC interface, indicating the corrosion pathway through the layer was oriented at an angle to the grinding plane. Sectioning was halted at the plane shown in Fig. 16b so that SEM analysis could be performed prior to risking further material 
removal to reveal the initial point of attack at the IPyC/SiC interface where the IPyC crack extended to the SiC and corrosion presumably initiated.
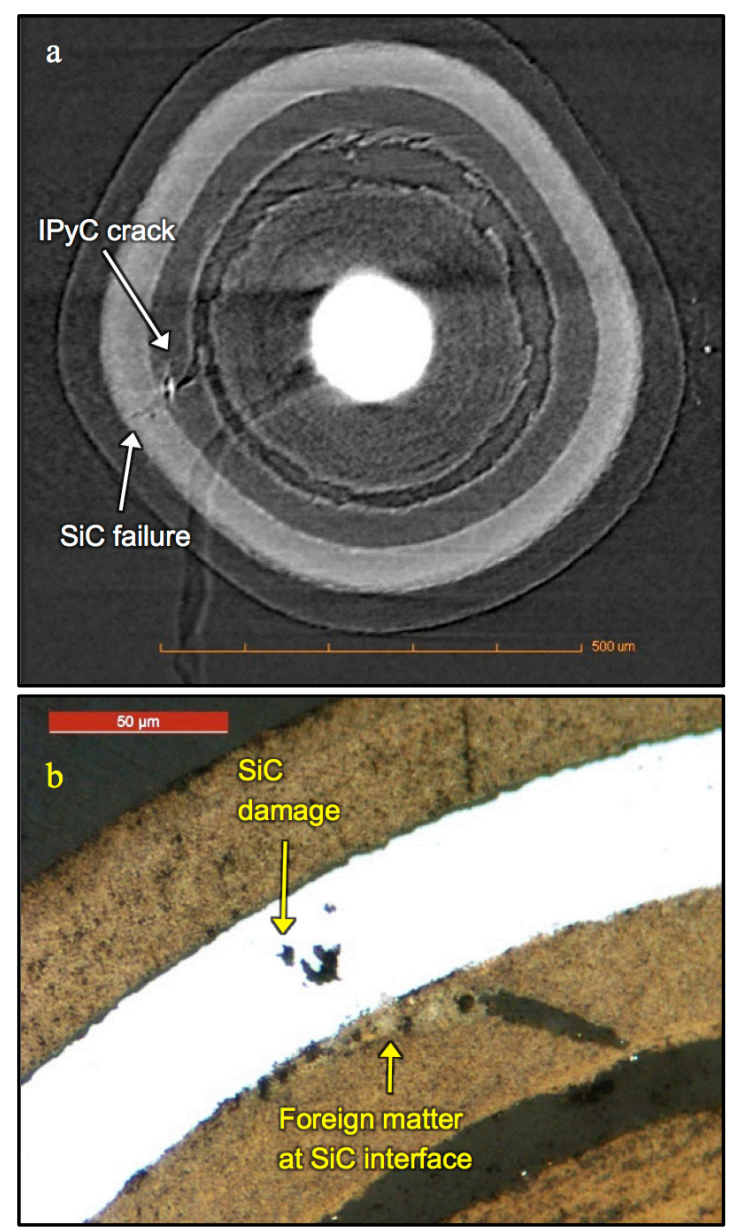

Fig. 16. Particle from Compact 5-2-1 that failed during irradiation testing; (a) x-ray tomograph oriented to show low-density pathway through SiC and (b) optical micrograph showing degraded area.

Fig. 17 shows a location on the outer edge of the soot inclusion in the cesium-releasing particle from Compact 3-3-2 where a crack extends from the defective $\mathrm{SiC}$ region through an intact overlayer. This particle was an interesting anomaly because the gross soot inclusion shown in Fig. 10 was present from the start of the AGR-1 irradiation test, yet the particle did not release cesium during the three-year experiment. This implies that the porous structure in the defective region did not present a connected pathway through the SiC layer and the abnormally-thin $\mathrm{SiC}$ acting to seal this area remained intact until failure after heating to $1600^{\circ} \mathrm{C}$. The crack shown in Fig. 17 was at least one through-layer defect that could have been responsible for the observed cesium release. 


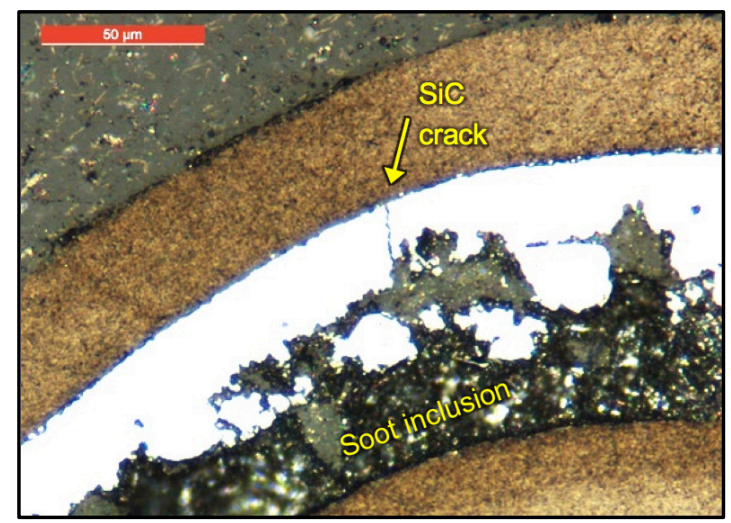

Fig. 17. Compact 3-3-2 particle with soot inclusion defect that failed during $1600^{\circ} \mathrm{C}$ safety testing. A crack through intact $\mathrm{SiC}$ covering the porous region produced a pathway through the layer.

\subsection{Analyzing SiC Failures with SEM}

Scanning electron microscopy was performed using a JEOL JSM-6390L SEM fitted with an Oxford INCA Energy 250 energy dispersive spectrometry (EDS) system. Imaging with backscattered electrons provided contrast as a function of atomic number (Z); metallic fission products clustered within the lower-Z TRISO layers appeared bright and could be targeted for elemental analysis with EDS.

Fig. 18 shows two parallel planar sections through one of the two particles recovered from Compact 3-3-1 that released cesium during $1700^{\circ} \mathrm{C}$ safety testing; these two planes are slightly offset in the grinding direction and reveal the same degraded pathway through the $\mathrm{SiC}$ at two different positions, similar to what was observed in the particle from Compact 5-2-1 (Fig. 16) as it was ground down due to the corrosion pathway being oriented at an angle to the grinding plane. The IPyC layer was decorated with high- $Z$ clusters that EDS identified as mostly uranium, except in the region surrounding the IPyC crack, where there appeared to be a depletion of these clusters. The corrosion pathway through the $\mathrm{SiC}$ was surrounded by numerous clusters of high- $\mathrm{Z}$ elements ranging in diameter from $<1$ to $5 \mathrm{~m}$ and identified by EDS to be predominantly palladium and uranium (these clusters may also contain silicon and carbon, which could not be resolved due to signal from surrounding material included in the electron excitation volume). Palladium and uranium were also observed at the IPyC/SiC interface around the entire circumference of the particle, but away from the degraded area, the IPyC/SiC interface remained intact and no significant $\mathrm{SiC}$ corrosion was observed. The predominance of palladium and uranium surrounding the degraded area, in conjunction with the free carbon that was observed within the area, suggests that these metals may have reacted with the $\mathrm{SiC}$ to form silicides that migrated away leaving a carbon filled pathway through the $\mathrm{SiC}$ that would not retain cesium. 


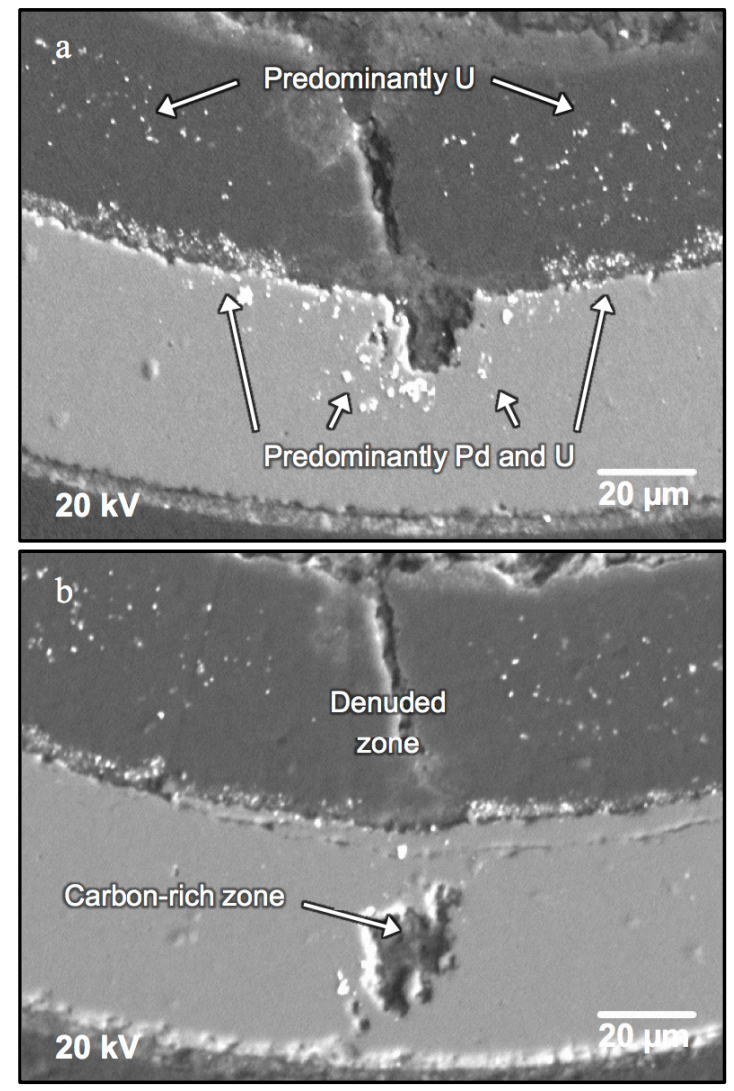

Fig. 18. Successive polished planar sections showing corrosion progression through SiC of Compact 3-3-1 Particle 2 after $1700^{\circ} \mathrm{C}$ safety testing.

Fig. 19 shows secondary and backscattered electron images of the degraded area in the SiC exposed by sectioning the other particle recovered from Compact 3-3-1 that released cesium during $1700^{\circ} \mathrm{C}$ safety testing. The exposed plane in this figure was prepared by grinding down from the top of the particle as shown in Fig. $7 \mathrm{~b}$ and stopping at the edge of the corrosion site before the center of the low-density feature was exposed. Similar to the left side of the degraded SiC area in Fig. 18a, a dense population of high-Z clusters was observed in this area. The secondary electron image (Fig. 19a) shows that the carbon-rich (gray) and metal-rich (white) features are flush with the polished surface and densely filling their resident volumes (except for the largest carbon-rich feature, which may have experienced some pullout during grinding and polishing). 


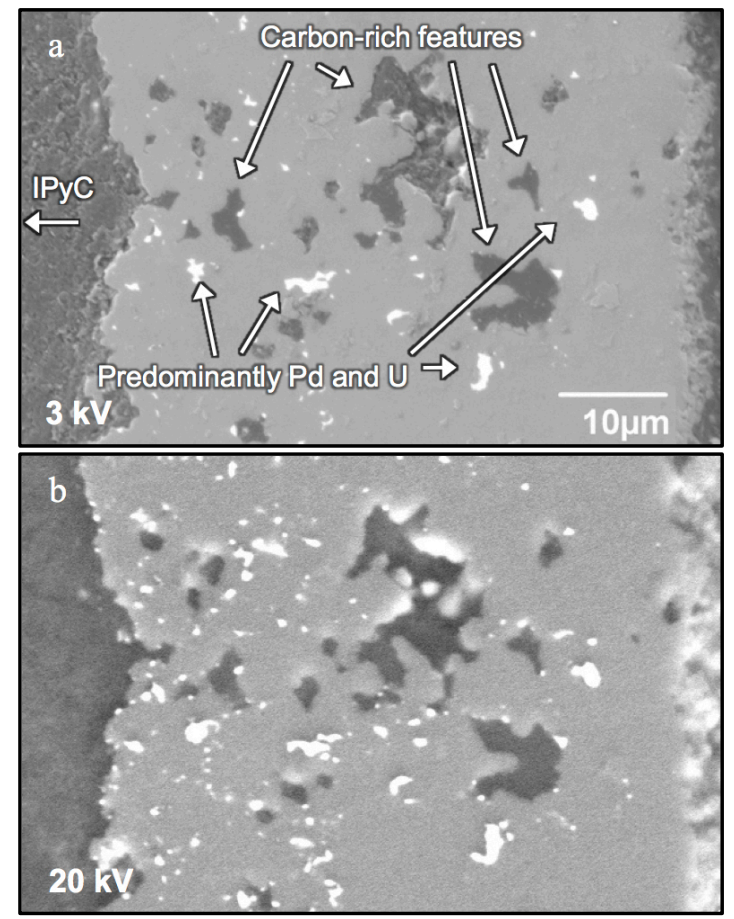

Fig. 19. Polished planar section through degraded $\mathrm{SiC}$ area in Compact 3-3-1 Particle 1 (Fig. $7 \mathrm{~b}$ ) after $1700^{\circ} \mathrm{C}$ safety testing; (a) scanning electron (SE) and (b) backscattered electron (BE) images that show numerous clusters of palladium and uranium and other areas that were predominately carbon. The SE image shows bright spots where Pd and $\mathrm{U}$ are embedded close to the surface, while the BE image shows additional Pd and U due to greater sensitivity and analysis depth.

\section{Enumerating particles in each compact with failed $\mathrm{SiC}$}

Determination of the number of particles in each compact with failed $\mathrm{SiC}$ was based on a combination of data on the amount of cesium released from the compact, the amount of exposed cesium still in the compact outside of intact SiC layers (measured by DLBL), and the amount of cesium retained by the particles with failed SiC that were separated out and measured by IMGA. The ${ }^{134} \mathrm{Cs}$ isotope was used for this analysis because DLBL results were sensitive to contributions from hot cell contamination and contamination levels in the hot cells where DLBL was performed were lower for the shorter-lived ${ }^{134} \mathrm{Cs}$ isotope. Particles with failed SiC were counted for 4-6 hours with the IMGA to acquire both ${ }^{134} \mathrm{Cs}$ and ${ }^{137} \mathrm{Cs}$ inventory data, which agreed well (varying by less than $5 \%$ ). Supporting data for counting particles with failed $\mathrm{SiC}$ involved enumeration of the low-cesium retaining particles found with IMGA (with examination by x-ray to verify the presence of failed $\mathrm{SiC}$ ) and additional DLBL data of uranium from exposed kernels indicative of the loss of particles with failed SiC during deconsolidation, leaching, and sieving prior to the IMGA survey. Table 1 and Table 2 present results using these two approaches. 
Table 1

Estimation of the number of particles with failed $\mathrm{SiC}$ based on recovery of ${ }^{134} \mathrm{Cs}$.

\begin{tabular}{|c|c|c|c|c|c|c|c|c|c|c|}
\hline & \multicolumn{3}{|c|}{ As-irradiated Compacts } & \multicolumn{3}{|c|}{$1600^{\circ} \mathrm{C}$ Safety Testing } & \multirow{2}{*}{$\frac{1700^{\circ} \mathrm{C}}{3-3-1}$} & \multicolumn{3}{|c|}{$1800^{\circ} \mathrm{C}$ Safety Testing } \\
\hline & $5-2-1$ & $5-2-3$ & $6-3-2$ & 3-3-2 & 4-1-2 & 6-4-1 & & $3-2-3$ & 4-4-1 & $5-1-3$ \\
\hline $\begin{array}{r}\text { Number of particles worth of }{ }^{134} \mathrm{Cs} \\
\text { detected outside compact }\end{array}$ & 0.28 & 0.27 & 0.96 & 0.89 & 0.69 & 0.49 & 1.49 & 6.62 & 1.49 & 4.87 \\
\hline $\begin{array}{r}\text { Number of particles worth of }{ }^{134} \mathrm{Cs} \\
\text { detected by DLBL }\end{array}$ & 0.20 & 0.20 & 0.30 & 0.01 & 0.02 & NA & 0.92 & 0.33 & 0.37 & 0.10 \\
\hline $\begin{array}{l}\text { Number of particles worth of }{ }^{134} \mathrm{Cs} \\
\text { retained in particles found with IMGA }\end{array}$ & 0.35 & 1.37 & NA & 0.03 & 0.01 & NA & 1.20 & 3.93 & 0.11 & 2.18 \\
\hline $\begin{array}{l}\text { Total number of particles worth of }{ }^{154} \mathrm{Cs} \\
\text { presumed to be associated with particles } \\
\text { that released }{ }^{134} \mathrm{Cs} \text { through failed } \mathrm{SiC}\end{array}$ & 0.83 & 1.84 & 1.27 & 0.93 & 0.71 & 0.49 & 3.61 & 10.89 & 1.97 & 7.15 \\
\hline $\begin{array}{l}\text { Estimated number of particles with } \\
\text { failed } \mathrm{SiC} \text { based on }{ }^{134} \mathrm{Cs} \text { accounting }\end{array}$ & 1 & 2 & 1 & 1 & 1 & 1 & 4 & 11 & 2 & 7 \\
\hline
\end{tabular}

NA denotes that data is not available because analysis was not performed.

For compacts safety tested at $1800^{\circ} \mathrm{C},{ }^{134} \mathrm{Cs}$ detected in post-burn leach of particles analyzed after IMGA survey was not included because a few particles with normal cesium retention were broken by the process and particles with failed SiC had already been removed from sample and accounted for with IMGA.

No low-cesium particles from Compact 4-4-1 were found with IMGA, but fragments from at least two particles, including one buffer-coated kernel, were

manually recovered after pre-burn leaching and gamma counted to measure ${ }^{134} \mathrm{Cs}$ inventory ( $\mathrm{SiC}$ in the recovered fragments showed signs of corrosion failure)

Table 2

Estimation of the number of particles with failed $\mathrm{SiC}$ based on identification by the IMGA and DLBL.

\begin{tabular}{|c|c|c|c|c|c|c|c|c|c|c|}
\hline & \multicolumn{3}{|c|}{ As-irradiated Compacts } & \multicolumn{3}{|c|}{$1600^{\circ} \mathrm{C}$ Safety Testing } & \multirow{2}{*}{$\begin{array}{c}1700^{\circ} \mathrm{C} \\
3-3-1 \\
\end{array}$} & \multicolumn{3}{|c|}{$1800^{\circ} \mathrm{C}$ Safety Testing } \\
\hline & $5-2-1$ & $5-2-3$ & 6-3-2 & 3-3-2 & $4-1-2$ & 6-4-1 & & $3-2-3$ & 4-4-1 & $5-1-3$ \\
\hline $\begin{array}{r}\text { Number of particles with failed SiC } \\
\text { found with IMGA }\end{array}$ & 1 & 2 & NA & 1 & 1 & NA & 2 & 9 & 0 & 5 \\
\hline $\begin{array}{r}\text { Number of particles worth of }{ }^{235} \mathrm{U} \\
\text { detected by DLBL }\end{array}$ & 0.27 & 0.24 & 1.13 & 0.82 & 1.13 & NA & 1.93 & 1.91 & 3.26 & 1.25 \\
\hline $\begin{array}{c}\text { Estimated number of particles with } \\
\text { failed SiC detected by DLBL }\end{array}$ & 0 & 0 & 1 & 1 & 1 & NA & 2 & 2 & 3 & 1 \\
\hline $\begin{array}{l}\text { Estimated total number of particles } \\
\text { detected by the IMGA and DLBL }\end{array}$ & 1 & 2 & 1 & 1 & 1 & NA & 4 & 11 & 3 & 6 \\
\hline
\end{tabular}

NA denotes that data is not available because analysis was not performed.

Compacts 3-3-2 and 4-1-2 each had one particle with failed SiC; uranium was leached prior to IMGA, but particles remained in one piece (Fig. 10 and Fig. 11) and were found during IMGA survey.

For compacts safety tested at $1800^{\circ} \mathrm{C},{ }^{235} \mathrm{U}$ detected in post-burn leach of particles analyzed after IMGA survey was not included because a few particles with normal cesium retention were broken by the process and particles with failed $\mathrm{SiC}$ had already been removed from sample and accounted for with IMGA.

While cesium and uranium measurements rarely summed to an integer value due to analysis uncertainty (typically $\sim 10 \%$ ), hot cell contamination, variation in actual isotopic content, and loss of volatile cesium during analysis, enumeration using the two methods in Table 1 and Table 2 agreed very well. Only two of the compacts safety tested at $1800^{\circ} \mathrm{C}$ yielded different estimated totals. Possible explanation for the disagreement for Compact 4-4-1 was that one particle broke during the sieving operation (indicated by uranium detected in the burn-leach of the matrix debris remaining after separating out the particles); some of the cesium from this particle would have been lost during the $750^{\circ} \mathrm{C}$ burn and not included in Table 1, resulting in a lower total count compared to Table 2 . In addition, the $\mathrm{SiC}$ in this particle may not have failed during safety testing (it may have been broken by handling during the sieving process), resulting in an overestimation of the number of particles with failed SiC in Table 2. It is unclear why the estimated totals for Compact 5-1-3 disagree; uncertainty in the ${ }^{134} \mathrm{Cs}$ analysis could be responsible.

A total of four particles with failed SiC were identified out of 298,000 particles included in the AGR-1 irradiation experiment. The small amount of uranium detected in Compacts 5-2-1 and 5-2-3 was not from exposed kernels, and more than $75 \%$ was located in the OPyC of the main particle sample, which didn't include the particles with failed $\mathrm{SiC}$. This uranium was presumably released during irradiation and represents a compact fractional release of about $6.5 \times 10^{-5}$. Compact 6-3-2 was examined at INL and DLBL was used, in lieu of IMGA survey, to determine that only one particle with failed $\mathrm{SiC}$ was responsible for most of the cesium release from that compact during irradiation. Slightly more than one particle's average inventory of cesium and uranium were detected, but these values would also be impacted by analysis uncertainties and low-level releases from particles with intact $\mathrm{SiC}$.

Only three particles with failed $\mathrm{SiC}$ were detected in compacts safety tested at $1600^{\circ} \mathrm{C}$, one from each of three compacts; a total of eight compacts $(\sim 33,100$ particles $)$ were tested at $1600^{\circ} \mathrm{C}$, with no failed $\mathrm{SiC}$ in the other five compacts. As shown in Fig. 10 and Fig. 11 and discussed in Section IV.A, the particles with failed SiC from Compacts 3-3-2 and 4-1-2 both had material missing from the kernel. This is in agreement with the uranium detected during DLBL of these compacts (Table 2). Compact 4-1-2 was missing its OPyC layer when recovered for IMGA and this presumably was fractured during the third 24-hour nitric acid leach performed on the deconsolidated particles, which was when $80 \%$ of the exposed uranium was detected. In contrast, most of the exposed uranium in Compact 3-3-2 (91\%) was detected during the matrix burn after pre-burn leaching and separation of the particles for IMGA survey; this suggests that uranium may have come out of the Compact 3-3-2 particle with failed $\mathrm{SiC}$ during irradiation. The fact that 3D $\mathrm{x}$-ray examination revealed no cracks in the pyrocarbon layers of this particle makes penetration of acid to the kernel unlikely. During irradiation, the kernel 
was only encapsulated by a very thin layer of intact $\mathrm{SiC}$ due to the gross soot inclusion. Uranium may have escaped through this thin SiC; as shown in Fig. 19, uranium can penetrate intact SiC, and SEM analysis has found uranium in the $\mathrm{SiC}$ layer up to $10 \mu \mathrm{m}$ from the IPyC interface of typical AGR-1 irradiated particles [Gerczak et al., 2014].

The likelihood of damaging particles during the deconsolidation, leaching, and sieving prior to IMGA survey seemed to increase for the higher temperature safety tests. This could be related to weakening of the OPyC layer, which was the only intact layer protecting the kernel from acid leaching in the particles with failed $\mathrm{SiC}$ recovered after 1700 and $1800^{\circ} \mathrm{C}$ safety testing. Materialography has revealed that the $\mathrm{SiC}$ and OPyC layers are often debonded and epoxy from vacuum backpotting can infiltrate this interface (Fig. 14), and as safety test temperature increases, the gap between the $\mathrm{SiC}$ and $\mathrm{OPyC}$ also increases (Fig. 7). Debonding of the OPyC may occur during irradiation as the matrix material shrinks away from the particles, pulling outward on the OPyC; the compact matrix can be expected to be more strongly bonded to the porous outer surface of the OPyC than the $\mathrm{OPyC}$ is bonded to the non-porous $\mathrm{SiC}$.

There was more variation in the number of $\mathrm{SiC}$ failures observed during the higher temperature safety testing. Two compacts $(\sim 8,300$ particles $)$ were tested at $1700^{\circ} \mathrm{C}$, with four failed-SiC particles in one and none in the other. Four compacts were safety tested at $1800^{\circ} \mathrm{C}$ ( 16,500 particles). Approximately twenty particles with $\mathrm{SiC}$ failures were detected in the three $1800^{\circ} \mathrm{C}$ compacts included in Table 1 and Table 2; and a fourth compact, Compact 4-3-2, was determined by separate analysis to most likely have had three particles with failed SiC [Demkowicz et al., 2015].

\section{Summary}

The focus of this paper has been on the detection and analysis of particles with failed $\mathrm{SiC}$ that exhibited cracking, structural defects, or chemical attack resulting in pathways through this layer that allowed the particles to release fractions of their cesium inventory. Because of this focus on failed $\mathrm{SiC}$, the spotlight has been on some of the ugliest and worst performing particles in the AGR-1 experiment. In perspective of the overall AGR-1 fuel performance, the particles discussed in this study represent $\mathrm{SiC}$ failure fractions of $1.3 \times 10^{-5}$ during irradiation, $9.1 \times 10^{-5}$ during $1600^{\circ} \mathrm{C}$ safety testing, $4.8 \times 10^{-4}$ during $1700^{\circ} \mathrm{C}$ safety testing, and $1.4 \times 10^{-3}$ during $1800^{\circ} \mathrm{C}$ safety testing. It should also be noted that compacts were held for 300 or more hours at the maximum safety-test temperature [Morris et al., 2014] and time was a factor in the number of particles that released cesium due to $\mathrm{SiC}$ degradation. Failure fractions at $1700^{\circ} \mathrm{C}$ and $1800^{\circ} \mathrm{C}$ would have been lower for shorter test periods.

Gamma scanning of the graphite holders that surrounded the compacts during irradiation testing was very successful in locating cesium release and identifying the compacts that had particles with through-layer pathways that caused the $\mathrm{SiC}$ to fail to retain cesium. Time-dependent monitoring of cesium condensation on water-cooled collectors was likewise successful in identifying SiC failure during safety testing, but resolving individual failure events became more difficult at higher temperature as the number of failures increased. Automated IMGA survey and three-dimensional x-ray tomography was shown to be very effective for isolating and identifying particles with failed SiC. Damage to particles during the deconsolidation, leaching, and sieving prior to the IMGA survey complicated the ability of IMGA to determine the total number of these abnormal particles in each compact, especially after safety testing at 1700 and $1800^{\circ} \mathrm{C}$; additional data from DLBL helped to supplement this analysis.

With the exception of two particles whose SiC layer failed to retain cesium due to cracking of layers already compromised by as-fabricated defects, the primary and only other observed failure mechanism started with radiation-induced buffer densification that sometimes caused the buffer to fracture and/or debond from the IPyC. Incomplete debonding at the buffer/IPyC interface sometimes resulted in the buffer changes causing the IPyC layer to crack and expose the $\mathrm{SiC}$. Exposed $\mathrm{SiC}$ was subjected to higher palladium and uranium concentrations, that were observed to be associated with localized degradation of the $\mathrm{SiC}$. Cesium release appeared to be caused by degradation pathways through the $\mathrm{SiC}$ layer, where silicide formation left carbon-rich zones in the $\mathrm{SiC}$ that would be permeable to cesium. Through-layer fracture of the $\mathrm{SiC}$ was not observed in conjunction with these degradation pathways in any of the particles that were recovered for microstructural analysis. The extent of the degradation and the number of particles that released cesium increased with increasing temperature.

\section{Acknowledgments}

This work was supported by the U.S. Department of Energy, Office of Nuclear Energy, under the Very High Temperature Reactor Technology Development Office Advanced Gas Reactor Fuel Development and Qualification Program. Assistance with quantitative analysis of actinide and fission product inventories was provided by the ORNL Nuclear Analytical Chemistry \& Isotopics Laboratory and the INL Analytical Laboratory, and many hot cell activities were performed by staff of the ORNL Irradiated Fuels Examination Laboratory and the INL Hot Fuel Examination Facility. 


\section{REFERENCES}

Baldwin, C.A., Hunn, J.D., Morris, R.N., Montgomery, F.C., Silva, C.M., Demkowicz, P.A., 2014. First Elevated-Temperature Performance Testing of Coated Particle Fuel Compacts from the AGR-1 Irradiation Experiment. Nucl. Eng. and Design 271, 131-141.

Demkowicz, P.A., Hunn, J.D., Morris, R.N., Harp, J.M., Winston, P.L., Baldwin, C.A., Montgomery, F.C., 2012. Preliminary Results of Post-Irradiation Examination of the AGR-1 TRISO Fuel Compacts, Paper HTR20123-021. In: Proceedings of HTR2012, Tokyo, Japan, October.

Demkowicz, P.A., Hunn, J.D., Morris, R.N., Baldwin, C.A., Harp, J.M., Winston, P.L., Ploger, S.A., Gerczak, T.J., van Rooyen, I.J., Montgomery, F.C., Silva, C.M., 2014. Irradiation Performance of AGR-1 High Temperature Reactor Fuel, Paper HTR2014-31182. In: Proceedings of HTR2014, Weihai, China, October.

Demkowicz, P.A., Reber, E.L., Scates, D.M., Scott, L., 2015. First High Temperature Safety Tests of AGR-1 TRISO Fuel with the Fuel Accident Condition Simulator (FACS) Furnace. J. Nucl. Mater. 464, 320-330.

Gerczak, T.J., Hunn, J.D., Baldwin, C.A., Morris, R.N., 2014. Fission Product Distribution in AGR-1 TRISO Fuel Particles with Varying Silver Retention. In: Proceedings of 2014 American Nuclear Society Annual Meeting, Reno, Nevada, USA, June.

Harp, J.M., Demkowicz, P.A., Ploger, S.A., 2012. Post-Irradiation Examination and Fission Product Inventory Analysis of AGR-1 Irradiation Capsules, Paper HTR2012-3-006. In: Proceedings of HTR2012, Tokyo, Japan, October.

Lowden, R.A., 2006. Fabrication of Baseline and Variant Particle Fuel for AGR-1. ORNL/CF-06/02. Oak Ridge, Tennessee: Oak Ridge National Laboratory.

Morris, R.N., Baldwin, C.A., Demkowicz, P.A., Hunn, J.D., Reber, E.L., 2014. Performance of AGR-1 HighTemperature Reactor Fuel During Post-Irradiation Heating Tests, Paper HTR2014-31135. In: Proceedings of HTR2014, Weihai, China, October.

Petti, D.A., Maki, J.T., Hunn, J.D., Pappano, P.J., Barnes, C.M., Saurwein, J.J., Nagley, S.G., Kendall, J.M., Hobbins, R.R., 2010. The DOE Advanced Gas Reactor Fuel Development and Qualification Program. JOM 62(9), 62-66.

Phillips, J.A., Barnes, C.M., Hunn, J.D., 2010. Fabrication and Comparison of Fuels for Advanced Gas Reactor Irradiation Tests, Paper 236. In: Proceedings of HTR2010, Prague, Czech Republic, October.

Ploger, S.A., Demkowicz, P.A., Hunn, J.D., Keyn, J.S., 2014. Microscopic Analysis of Irradiated AGR-1 Coated Particle Fuel Compacts. Nucl. Eng. and Design 271, 221-230.

Scates, D.M., 2010. Fission Product Monitoring and Release Data for the Advanced Gas Reactor -1 Experiment, Paper 52. In: Proceedings of HTR2010, Prague, Czech Republic, October.

Note to the Editors:

References [Demkowicz et al, 2014] and [Morris et al., 2014] are to be published in the same NED issue as this paper. Is it possible to update these citations? 